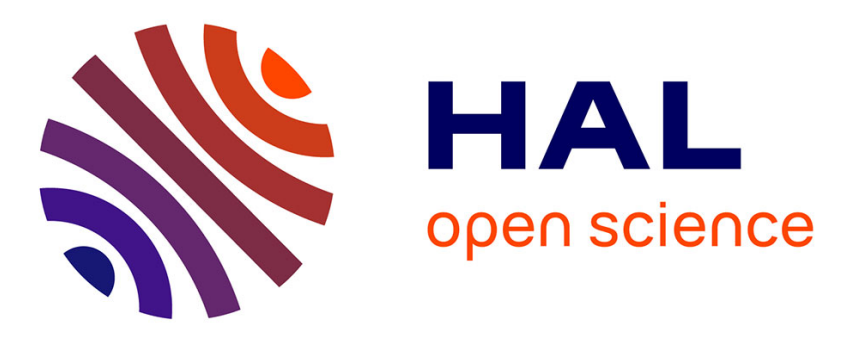

\title{
Steam explosion of beech wood-effect of the particle size on the xylans recovery
}

E. Simangunsong, Isabelle Ziegler-Devin, Laurent Chrusciel, Pierre Girods, $\mathrm{Nj}$. Wistara, Nicolas Brosse

\section{> To cite this version:}

E. Simangunsong, Isabelle Ziegler-Devin, Laurent Chrusciel, Pierre Girods, Nj. Wistara, et al.. Steam explosion of beech wood-effect of the particle size on the xylans recovery. Waste and Biomass Valorization, 2019, 11 (2), pp.625. 10.1007/s12649-018-0522-4 . hal-02125966

\section{HAL Id: hal-02125966 \\ https://hal.univ-lorraine.fr/hal-02125966}

Submitted on 10 May 2019

HAL is a multi-disciplinary open access archive for the deposit and dissemination of scientific research documents, whether they are published or not. The documents may come from teaching and research institutions in France or abroad, or from public or private research centers.
L'archive ouverte pluridisciplinaire HAL, est destinée au dépôt et à la diffusion de documents scientifiques de niveau recherche, publiés ou non, émanant des établissements d'enseignement et de recherche français ou étrangers, des laboratoires publics ou privés. 


\title{
STEAM EXPLOSION OF BEECH WOOD- EFFECT OF THE PARTICLE SIZE ON THE XYLANS RECOVERY
}

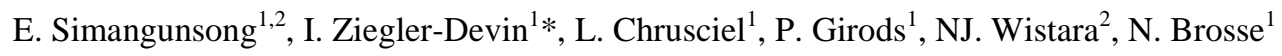 \\ ${ }^{1}$ Université de Lorraine, LERMAB, EA 4370, Faculté des Sciences et Technologies, BP 239, \\ 54506 Vandoeuvre lès Nancy, France, ${ }^{2}$ Department of Forest Products, Faculty of Forestry, \\ Bogor Agricultural University, 16680 Bogor, Indonesia
}

*Corresponding author

E-mail: isabelle.ziegler@univ-lorraine.fr

Phone: + 332745613

\begin{abstract}
In this work the effect of particle size and of the severity factors were investigated to find the optimum condition of steam explosion pretreatment on xylan recovery of beech wood. The beech wood particle with sizes of $0.16,1$, or $2 \mathrm{~mm}$ were steamed at $150^{\circ} \mathrm{C}-210^{\circ} \mathrm{C}$ for $2.5-15$ minutes before the explosive decompression. The results showed that the maximum xylan recovery was about $10 \% \mathrm{w} / \mathrm{w}$ wood with low concentration of the inhibitors, which were obtained when the particle size is $1 \mathrm{~mm}$ and $\mathrm{R}_{0}=3.65\left(190^{\circ} \mathrm{C}, 10 \mathrm{~min}\right)$. The smaller particle size may result in overcooking of biomass, lead to easily and high degradation of hemicellulose sugars, whereas the larger particle size may result in incomplete autohydrolysis in biomass and lower extractability of hemicellulose sugars. The obtained optimum condition for xylan recovery will improve the subsequent utilization (such as in food industry and other chemical products), prior to subsequent transformation of steam explosion pretreated wood (bioethanol and pellet).
\end{abstract}

Keywords: Steam explosion pretreatment; beech wood; severity factor; biomass particle size; xylan recovery.

\section{Graphical abstract}

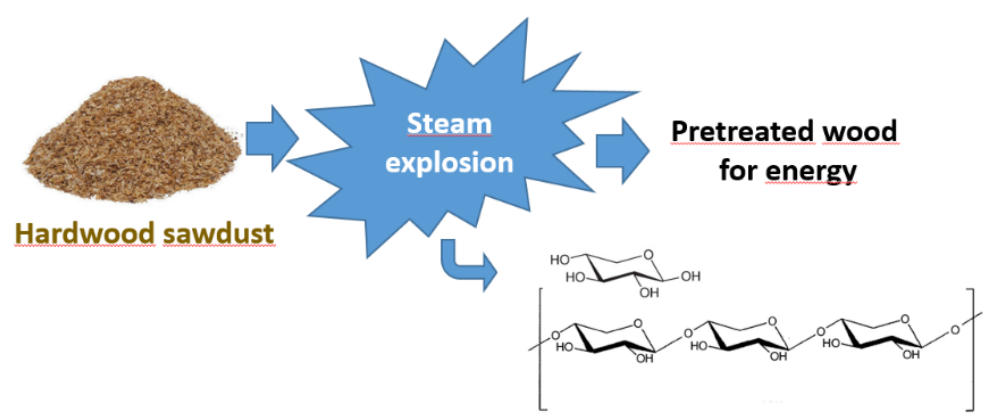

\section{Statement of Novelty :}

The steam explosion pretreatment of beech sawmill has been studied. The effect of hardwood chips particle size on the sugars recovery (xylose and xylans) in the liquid stream has been examined for the first time. The final goal is the improved valorization of the xylans from hardwood sawmill waste. 


\section{Introduction}

The steam explosion (SE) process was developed by Mason in 1924 for the production of chipboard panels [1] and then improved for lignocellulosic materials disintegration used in the manufacture of paper, board pulp and the like [2]. The main equipment of this process is a steam generator, high-pressure reactor, an explosion tank to receive the material after explosion and a condenser [3]. SE is a pretreatment process to open up the biomass fibers. It uses high temperature and pressure steam for certain duration of times proceeded by a sudden pressure drop causing the disintegration of lignocellulosic structure and lower the bulk density of biomass [4-5]. SE is a thermo-mechanico-chemical pretreatment which induces a breakdown of lignocellulose by chemical modifications from in situ generated acids which cause the depolymerisation of hemicelluloses and by mechanical action due to high shearing forces applied to the biomass during the explosive release. This process improves the recovery of sugars (or other useful compounds) and so, makes the biopolymers more accessible for subsequent processes such as fermentation or densification. It can be used as a pretreatment process to produce solid biofuel pellets, to increase the calorific value, to improve the pelletizing properties of the biomass or to make cellulose more accessible to enzymes in order to convert it to fermentable simple sugars [6-7].

SE has been extensively described for pretreatment to enhance (1) the enzymatic hydrolysis of the resulting cellulosic pulp (poplar wood, sugar cane bagasse, pine wood, douglas wood, corn stover, and wheat bran [8-13] and (2) the properties of pellets from agricultural-based biomass, poplar wood, and douglas wood [4, 11-12]. In addition to the pretreated cellulosic pulp, high yields of hemicellulosic sugars are recovered in the water effluent of SE process. These sugars consist of monomers, oligomers and polymers which constitute attractive building blocks for further transformations. The kinetics of hydrolysis of corn cob and eucalypus globulus xylans have been accurately described during hydrothermal treatments $\left(150^{\circ} \mathrm{C}-190^{\circ} \mathrm{C}\right.$, few hours). However, the parametric factors affecting the hemicellulosic sugars recovery during the cooking step of a SE treatment are not fully understood. No clear correlation between temperature, residence time, biomass particle size and hemicellulosic sugars yields has been found in the literature.

Severity factor is a model broadly used for evaluating the process of pretreatment. It is based on the assumption that overall the pretreatment process is hydrolytic, and it follows a first order of kinetics process and obeys the Arrhenius law [14]. It combines the treatment temperature (T) and residence time $\left(\mathrm{t}_{\mathrm{s}}\right)$ in one value.

During the cooking step of SE, hydronium ions from both water and in-situ generated compounds catalyze the hemicellulose depolymerization into oligomers and monomers (autohydrolysis process) [15-16]. Under harsh conditions (high temperature, low $\mathrm{pH}$ ), monomeric sugars can be further degraded to furan derivatives (furfural from $\mathrm{C} 5$ and hydroxymethylfurfural from C6 sugars).

However, one of the limitations of the severity index model is the lacking particle size informations that have a major influence on the kinetics of the hydrolytic process. Particle size strongly affects the kinetics of the hydrolytic processes, the efficiency of the vapor soaking, the particles heat transfer and physical modifications of the biomass [12, 17-18]. Size reduction of biomass before a pretreatment is crucial for the optimization of sugars conversion but also strongly affect the milling power and the overall cost of the process [10].

Large particle size can hamper heat transfer and may result in incomplete auto-hydrolysis of its interior part whereas small particle may result in overcooking and in a degradation of its components. In the literature, the effect of chip size on SE process has been examined regarding 
the sugars recovery starting from agricultural residues [12] and on softwood [10, 19]. It was concluded that larger particle produced higher enzymatic cellulosic pulp digestibility. The effect of the chips size on the sugars recovery and the furans production have also been examined during the SE of Douglas-fir [17]. To the best of our knowledge, the effect of hardwood chips particle size on SE performance and on sugars recovery in the liquid stream of the SE has never been examined.

European Beech (Fagus sylvatica L.) is one of the most abundant species and the most harvested hardwood in France. It is used to produce sawn wood with an average yield of 43-50\% [20-21]. As a result, considerable amount of wood residues is produced which could constitute a potential source of biopolymers and/ bioenergy. Xylans are the main hemicellulosic components of beech wood. They constitute a valuable potential source for the production of high-added value ingredients for functional foods (xylo-oligosaccharides and/or xylitol from xylose) [22-23].

In the present study, the effect of the size of beech sawdust pretreated by varying experimental SE conditions (temperature, residence time) on the sugars conversion was examined in order to assess which SE conditions produce the maximum concentration of sugars (monomers and oligomers) in the water stream. The final goal is to improve the extraction of xylan of beech sawmill waste.

\section{Material and methods}

\subsection{Process flow chart}

Fig. 1 presents the different steps used to characterize beech wood (extractibles, ash, lignin, cellulose and hemicelluloses) and to process to beech wood preatment by using steam explosion (SE) process.

\subsection{Sample preparation}

The wood used in this study was beech (Fagus sylvatica L.) from Lorraine forest. The wood samples were milled and sieved with three different sizes: $2 \mathrm{~mm}, 1 \mathrm{~mm}$, and $0.160 \mathrm{~mm}$. Then the sample were dried and stored at room temperature until steam explosion pretreatment.

\subsection{Chemical composition}

Extractives: In a Soxhlet apparatus, $2 \mathrm{~g}$ dry sample with particle size $0.160 \mathrm{~mm}$ were extracted for 16 cycles with $300 \mathrm{~mL}$ of toluene and ethanol $(2 / 1 ; \mathrm{v} / \mathrm{v})$. The solvent was then evaporated under vacuum and the extracts were weighed, whereas the beech sample was dried with temperature $40^{\circ} \mathrm{C}$ for 24 hours. Extractives content were calculated by using these two-final masses.

Holocellulose: $1.5 \mathrm{~g}$ of beech free extractive samples with particle size $0.160 \mathrm{~mm}, 1 \mathrm{~g}$ of sodium chlorite $\left(\mathrm{NaClO}_{2}\right), 1 \mathrm{~mL}$ acetic acid $\left(\mathrm{CH}_{3} \mathrm{COOH}\right)$ glacial and $125 \mathrm{~mL}$ ultrapure water (UPW) were mixed into a $250 \mathrm{~mL}$ flask. The flask was brought to reflux with continuous stirring for 2 hours at $70^{\circ} \mathrm{C}$. Every 2 hours, $1 \mathrm{~g} \mathrm{NaClO} 2$ and $1 \mathrm{~mL} \mathrm{CH}_{3} \mathrm{COOH}$ were added until the wood sample is completely white, meaning a total delignification. The solid fraction of holocellulose was then washed with ultrapure water then filtered, and finally dried at $40^{\circ} \mathrm{C}$ for 24 hours and then weighed. Holocellulose content was calculated by using the mass change.

Cellulose: $1 \mathrm{~g}$ of previous holocellulose was mixed with $50 \mathrm{~mL}$ of sodium hydroxide $(\mathrm{NaOH}-$ $17,5 \%$ ) in a $100 \mathrm{~mL}$ Erlenmeyer flask for 30 minutes at $25^{\circ} \mathrm{C}$. Then, about $5 \mathrm{~mL}$ ultrapure water was added and stirred for 30 minutes at $25^{\circ} \mathrm{C}$. The solid part, composed of cellulose, was filtered and washed with $50 \mathrm{~mL}$ of a solution of acetic acid (1\% in volume). The solid was dried in oven at $40^{\circ} \mathrm{C}$ for 24 hours and weighed. Cellulose content was calculated by using the mass variation. 
Lignin: $0.175 \mathrm{~g}$ of wood free extractive with particle size $0.160 \mathrm{~mm}$ was put inside a plastic centrifuge-tube. About $1.5 \mathrm{~mL}$ sulfuric acid $\left(\mathrm{H}_{2} \mathrm{SO}_{4}-72 \%\right)$ were mixed with the sample and then incubated in a rotary water bath for at $30^{\circ} \mathrm{C}$ for 1 hour. The sample was taken out and $42 \mathrm{~mL}$ of ultrapure water were added. The tube was then closed and put inside an autoclave for 1 hour 30 minutes. The solid, composed of insoluble lignin - also known as Klason lignin -, was filtered, washed, dried at $105^{\circ} \mathrm{C}$ for $24 \mathrm{~h}$ and finally weighed. The liquid phase, containing monomeric sugars from cellulose and hemicelluloses, was completed with ultrapure water to $100 \mathrm{~mL}$ and freezed for further analyses. Lignin content was calculated by using the mass variation, whereas monomeric sugars were quantified by High-Performance Anion Exchange Chromatography coupled with Pulsed Amperometric Detection (HPAE-PAD).

Ash: $1 \mathrm{~g}$ of dry sample was weighed into a tared crucible and then put inside a muffle furnace (Carbolite WF-1100) with a temperature of $525^{\circ} \mathrm{C}$ for 24 hours. After 24 hours, the crucible was stored in a desiccator and weighed. The ash content was be obtained by the decrease in mass.

Oligomeric sugars post-hydrolysis: To be quantified, oligomeric sugars contained in the liquid fraction after SE were first hydrolyzed to monomeric sugars. $10 \mathrm{~mL}$ of SE liquid phase were mixed in a plastic centrifuge-tube with $349 \mu \mathrm{L}$ of sulfuric acid $\left(\mathrm{H}_{2} \mathrm{SO}_{4}-72 \%\right)$ and autoclaved at $121^{\circ} \mathrm{C}$ for $1 \mathrm{~h}$. After a subsequent dilution (200 times), the monosaccharide content of the sample was then determined by HPAE-PAD.

\subsection{Chromatographic analyses}

HPAE-PAD analysis: Monosaccharide contents of soluble fractions were analyzed by HPAEPAD (ICS-3000 Dionex) equipped with a Dionex CarboPacTM PA-20 (3x150 mm) analytical column. Filtered samples $(20 \mu \mathrm{L})$ were eluted at $35^{\circ} \mathrm{C}$ and at $0.4 \mathrm{~mL} / \mathrm{min}$ with the following composition: UPW 99,2\% /250mM NaOH $0,8 \%: 0 \rightarrow 20 \mathrm{~min}$; UPW $75 \% / 250 \mathrm{mM} \mathrm{NaOH} 20 \%$ $/ \mathrm{NaOAc}(1 \mathrm{M})-\mathrm{NaOH}(20 \mathrm{mM}) 5 \% 20 \rightarrow 37 \mathrm{~min} ; \mathrm{UPW} 40 \% / 250 \mathrm{mM} \mathrm{NaOH} 20 \% / \mathrm{NaOAc}(1 \mathrm{M})-$ $\mathrm{NaOH}(20 \mathrm{mM}) 40 \% 37 \rightarrow 41 \mathrm{~min}$. Each elution was followed by a wash and subsequent equilibration time. External sugar and uronic acids standards were used for calibration (7 points per curve) : fucose, glucose, xylose, galactose, mannose, rhamnose, arabinose and galacturonic acide, glucuronic acid (all provided by Sigma-Aldrich).

High-Performance Liquid Chromatography (HPLC) analysis: During SE, acetic acid can be released from the wood because of the partial hydrolysis of its cell wall components; whereas furfural and 5-hydroxymethylfurfural (HMF) can be produced respectively from pentose sugars and hexose sugars by a dehydration process. At last formic and levulinic acids are resulting from both furans degradation.

All these "by-products" were analyzed by HPLC (Ultimate 3000) using a Rezex ${ }^{\mathrm{TM}}$ RHMMonosaccharide $\mathrm{H}^{+}(8 \%)$ column with sulfuric acid $\left(\mathrm{H}_{2} \mathrm{SO}_{4}-5.10-3 \mathrm{M}\right)$ as the mobile phase with an isocratic flow rate of $0,8 \mathrm{~mL} / \mathrm{min}$ and a temperature of $65^{\circ} \mathrm{C}$. The wavelength for detecting the three acid compounds was $210 \mathrm{~nm}$, whereas it was $280 \mathrm{~nm}$ for furfural ad HMF. Each elution was followed by a wash and subsequent equilibration time. External standards provided by Sigma-Aldrich were used for calibration (5 points per curve).

\subsection{Steam explosion pretreatment}

The wood samples $(1 \mathrm{~mm}, 2 \mathrm{~mm}$, and $0.160 \mathrm{~mm}$ ) were impregnated in the ultrapure water for 24 hours at the room temperature beforehand; with a ratio between water and wood sample of 20:1 $(\mathrm{v} / \mathrm{w})$. After the sample was soaked, it was filtered; the filtered-water was stored for the analysis of sugar content. The framework of steam explosion process is shown in Fig. 2; the apparatus is composed of three main parts : a vapor generator, a reactor and a discharge tank. 
The $20 \mathrm{~g}$ of beech wood sample was loaded into the reactor and exposed to the several highpressure steams [3,7 bar - 18,1 bar] for several residence times [2 min-15 min] and temperatures $\left[150^{\circ} \mathrm{C}-210^{\circ} \mathrm{C}\right]$. The samples were then exploded by sudden-dropped in pressure and released in the discharge tank. The exploded solid biomass was separated from the liquid fraction by vacuum filtration. It was dried at $40^{\circ} \mathrm{C}$ for 48 hours, whereas the volume of liquid fraction was measured; only a small part was frozen until it was analyzed for monomeric and oligomeric sugars content and other byproducts.

Severity factor:

$$
R_{0}=\int_{0}^{t_{s}} \exp \left(\frac{T-100}{14.75}\right) d t
$$

Where:

Ro = Severity factor

$\mathrm{Tr}=$ Temperature of reaction $\left({ }^{\circ} \mathrm{C}\right)$

$\mathrm{Tb}=$ Base temperature $\left(100^{\circ} \mathrm{C}\right)$

ts $=$ Residence time ( $\mathrm{min})$

$14,75=$ Conventional activation energy with assumption overall process is hydrolytic, follows the first order of kinetics process, and obey Arrhenius law.

\section{Results and Discussion}

3.1 Chemical composition

The untreated beech wood used in this study comprises $37.8 \%$ cellulose, $35.7 \%$ hemicellulose, $24.5 \%$ Klason lignin, $1.8 \%$ extractives (solubility in toluene and ethanol; $2 / 1$; v/v, respectively) and $0.2 \%$ ash. Compared to some reports from literature, the sample has lower amount of cellulose and higher or comparable content of lignin [24-27].

\subsection{Overall mass loss to severity factor}

The SE experimental conditions used were as follows: temperature from $150^{\circ} \mathrm{C}$ to $210^{\circ} \mathrm{C}$, residence time from $2.5 \mathrm{~min}$ to $15 \mathrm{~min}$, sawdust sizes of $0.16 \mathrm{~mm}, 1 \mathrm{~mm}$, and $2 \mathrm{~mm}$. The corresponding severity factors are gathered in Table 1. As seen in Figure 3, the mass loss was increasing with the severity factor. It appears that below a severity factor of 3.0, the mass loss was varying very slightly whatever the size of the particle. For $\mathrm{R}_{0}>3.0$, dramatic increase of the mass loss was observed. At the highest severity $\left(R_{0}=4.41\right), \sim 40 \%$ of the wood was solubilized. This result is in accordance with previous works performed starting with hardwood chips using both continuous [28] or batch [28-29] SE systems which showed that a significant degree of solubilization of wood requires treatment severity beyond $\mathrm{R}_{0}=3.0$ with a maximum $(\sim 30 \%$ of mass loss) for $\mathrm{R}_{0}>3.75$. From Fig. 3 it can be seen that the particle sizes impact the mass loss. The larger particles exhibited a significantly lower degree of wood solubilization.

\subsection{Xylan and glucan yields}

Figure 4A, B and C give respectively the total monosaccharides yields, the monomeric glucose and the monomeric xylose released in the liquid phase during the steam explosion process as a function of the severity factors. As expected, the sugars yields recovered in the liquid phase follow the same trend as the mass losses (Fig. 3). For $R_{0}<3.0$, the sugars yields were very low and slightly increase with $\mathrm{R}_{0}$. For $\mathrm{R}_{0}>3.0$, an increase is observed.

As expected, the xylose concentrations (Fig 4C) are higher than those of the other sugars, xylan being the dominant hemicellulose of beech. For instance, with a severity factor of 4.41 , xylose represents about $75 \%$ of the sugars released whatever the sawdust size. Its yield was increasing 
drastically when the $\mathrm{R}_{0}>3.0$, confirming that hydrolysis of hemicelluloses is more efficient when increasing severity factor. Regarding glucose content, its value is very low compared to the total yield of monosaccharides. Glucose yields are more difficult to interpret because glucose is produced by the hydrolysis of both hemicellulose and cellulose. The low glucose content in the hydrolysates showed that cellulose was not or few affected by steam explosion process in our conditions.

Interestingly, higher monosaccharides content is recovered in solution for the intermediate particle size $(1 \mathrm{~mm})$; for larger $(2 \mathrm{~mm})$ or smaller $(0.16 \mathrm{~mm})$ particles lower sugars concentrations were detected. This result is in agreement with previous studies performed on softwood (Douglas-Fir), in which fine particles $(0.42 \mathrm{~mm})$ released fewer sugars than woodchips [17].

The yields of the oligomeric total sugars, glucans and xylans released during the SE process in the liquid phase are shown in Fig. 5A, B and C respectively. Fig. 5B and $\mathrm{C}$ confirm that xylans are the dominant polysaccharides (> 77\% of total sugars). Compared to monosaccharides, the oligomeric contents are higher and the shape of the curves are different; the oligosaccharides are released at lower $\mathrm{R}_{0}$ (from $\mathrm{R}_{0}=2.5$ ) and reach a maximum at $\mathrm{R}_{0}=3.65\left(190^{\circ} \mathrm{C}, 10\right.$ minutes). At that severity, the amount of extracted oligosaccharides was $10 \mathrm{~g} / 100 \mathrm{~g}$ of dry wood for xylans and $0.8 \mathrm{~g} / 100 \mathrm{~g}$ of dry wood for glucans.

A further increase in severity led to a decrease in the recovery of oligosaccharides. This can be explained by the kinetic pathway in which oligomers are released first during the steam treatment and then are further hydrolyzed into monosaccharides [16, 31]. Very similar results were previously reported for the non-catalyzed SE of poplar using a continuous $4 \mathrm{t} / \mathrm{h}$ pilot plant [28]. These authors described a maximum pentosans recovery (monomers and oligomers) of $65 \%$ at $\mathrm{R}_{0}=3.8$. In contrast, using acid-catalyzed $\mathrm{SE}$, pentosans and hexosans were primarily recovered as monosaccharides. At $\mathrm{R}_{0}=3.03$, less than $20 \%$ of xylans were found as oligomers [32].

Regarding the influence of the particle size, as it was previously observed for monomeric sugars, the oligomeric recovery in the liquid phase is higher starting from a sawdust size of $1 \mathrm{~mm}$.

\subsection{Furfural and 5-HMF yields}

During the cooking step of SE process, the increase of severity led to an increasing content of hemicelluloses solubilized and to an increasing dehydration rate of sugars derived from hemicellulose, producing byproducts such as furfural and 5-hydroxymethylfurfural (HMF) [33]. In a biomass-to-biofuel process, furfural and HMF might affect enzymes in hydrolysis process and reduce glucose conversion during fermentation process [34]. As shown in Fig. 6, the concentration of HMF and furfural in the SE liquid effluents were undetectable or very low for $\mathrm{R}_{0}<3.5$ and increased above this value. For the highest severity $\left(\mathrm{R}_{0}=4.41\right)$ and the smallest particle size $(0.16 \mathrm{~mm})$, maximum concentration of $\operatorname{HMF}(0.2 \% \mathrm{w} / \mathrm{w})$ and furfural $(0.7 \% \mathrm{w} / \mathrm{w})$ were detected. Stoffel et al (2017) reported comparable trends but the generation of higher levels of degradation products during the SE of pine sawdust [32]. In this study the higher furans content in the hydrolysates can be rationalized by the utilization of 1-3\% of sulfuric acid as catalyst which catalysis the sugars dehydration reactions.

The impact of the wood particle size on the production of degradation products is clearly shown in Fig. 6 the smaller the particle, the higher the furfural and HMF concentration. Similar results were described by Cullis et al. (2004) who observed during the SE of softwood a substantial decrease of the production of furfural and HMF as the wood chip size increased (from $1.5 \mathrm{~cm}$ to $5 \mathrm{~cm}$ ) [17]. Overcooking of the small particles during the cooking step of SE may promote hemicelluloses depolymerization and degradation. Surprisingly, Liu et al. (2013) reported the 
opposite trend for the SE of corn stover : the amount of furan derivatives was higher and the sugars recoveries were lower for larger biomass particules [12].

\section{Conclusion}

The optimization of pretreatment of beech wood by uncatalyzed SE for hemicellulose recovery in the forms of monomeric and oligomeric is as a fuction of the severity factor and particle size. The maximum of oligomers recovery was obtained when the particle size is $1 \mathrm{~mm}$ and $\mathrm{R}_{0}=3.65$, $10 \% \mathrm{w} / \mathrm{w}$ wood with low concentration of the inhibitors. The particle size is a very important factor in the hemicellulose recovery and in this work the optimum size was found to be $1 \mathrm{~mm}$. Smaller particle size $(0.16 \mathrm{~mm})$ resulted in overcooking of biomass, leading to higher degradation of hemicellulose sugars, whereas larger particle size $(2 \mathrm{~mm})$ resulted in incomplete autohydrolysis in biomass and lower extractability of hemicellulose sugars. The optimum condition for xylan recovery will optimize the subsequent utilization (such as in food industry and other chemical products), prior to subsequent transformations of SE pretreated wood (bioethanol and pellet).

\section{Acknowledgements}

We acknowledge financial support of LERMAB which supported by the French National Research Agency through the Laboratory of Excellence ARBRE (ANR-12- LABXARBRE-01) and Double Degree Master Program of Indonesia Ministry of Education and Culture.

\section{References}

1. Jacquet, N., Maniet, G., Vanderghem, C., Delvigne, F., Richel, a.: Application of Steam Explosion as Pretreatment on Lignocellulosic Material: A Review. Ind. Eng. Chem. Res. 54, 2593-2598 (2015). doi:10.1021/ie503151g

2. Mason, W.H.: Process and Apparatus For Disintegration of Wood and The Like, (1926)

3. Akinlabi, E.T., Anane-Fenin, K., Akwada, D.R.: Bamboo as fuel. In: Bamboo: The Multipurpose Plant. p. 170 (149-178). Springer International Publishing (2017)

4. Adapa, P., Tabil, L., Schoenau, G.: Grinding performance and physical properties of nontreated and steam exploded barley, canola, oat and wheat straw. Biomass and Bioenergy. 35, 549-561 (2011). doi:10.1016/j.biombioe.2010.10.004

5. Gong, L., Huang, L., Zhang, Y.: Effect of steam explosion treatment on barley bran phenolic compounds and antioxidant capacity. J. Agric. Food Chem. 60, 7177-7184 (2012). doi:http://dx.doi.org/10.1021/jf301599a

6. Lam, P.S., Lam, P.Y., Sokhansanj, S., Bi, X.T., Lim, C.J.: Mechanical and compositional characteristics of steam-treated Douglas fir ( Pseudotsuga menziesii L . ) during pelletization. Biomass and Bioenergy. 56, 116-126 (2013). doi:10.1016/j.biombioe.2013.05.001 
7. Mosier, N., Wyman, C., Dale, B., Elander, R., Lee, Y.Y., Holtzapple, M., Ladisch, M.: Features of promising technologies for pretreatment of lignocellulosic biomass. Bioresour. Technol. 96, 673-686 (2005). doi:10.1016/j.biortech.2004.06.025

8. Grous, W.R., Converse, A.O., Grethlein, H.E.: Effect of steam explosion pretreatment on pore size and enzymatic hydroxlysis of poplar. Enzyme Microb. Technol. 8, 274-280 (1986)

9. Kling, S.H., Neto, C.C., Ferrara, M.A., Torres, J.C.R., Magalhaes, D.B., Ryu, D.D.Y.: Enhancement of Enzymatic Hydrolysis of Sugar Cane Bagasse by Steam Explosion Pretreatment. Biotechnol. Bioeng. XXIX, 1035-1039 (1987)

10. Ballesteros, I., Oliva, J.M., Navaro, A.A., González, A., Carrasco, J., Ballesteros, M.: Effect of Chip Size on Steam Explosion Pretreatment of Softwood. Appl. Biochem. Biotechnol. 84$86,97-110(2000)$

11. Kumar, L., Chandra, R., Saddler, J.: Influence of Steam Pretreatment Severity on PostTreatments Used to Enhance the Enzymatic Hydrolysis of Pretreated Softwoods at Low Enzyme Loadings. Biotechnol. Bioeng. 108, 2300-2311 (2011). doi:10.1002/bit.23185

12. Liu, Z., Qin, L., Pang, F., Jin, M., Li, B., Kang, Y., Dale, B.E., Yuan, Y.: Effects of biomass particle size on steam explosion pretreatment performance for improving the enzyme digestibility of corn stover. Ind. Crop. Prod. 44, 176-184 (2013). doi:10.1016/j.indcrop.2012.11.009

13. Jiang, S., Guo, N.: The steam explosion pretreatment and enzymatic hydrolysis of wheat bran. Energy Sources. 38, 295-299 (2016). doi:10.1080/15567036.2012.744118

14. Chornet, E., Overend, R.P.: Phenomenological Kinetics and Reaction Engineering Aspects of Steam/Aqueous Treatments. In: Proceeding of the International Workshop on Steam Explosion Techniques: Fundamentals and Industrial Applications. pp. 21-58. Gordon and Breach Science Publisher (1988)

15. Xiao, L.-P., Song, G.-Y., Sun, R.-C.: Effect of Hydrothermal Processing on Hemicellulose Structure. In: Hydrothermal Processing in Biorefineries: Production of Bioethanol and High Added-Value Compounds of Second and Third Generation Biomass. pp. 45-93. Springer International Publishing (2017)

16. Tunc, M.S., Van Heiningen, A.R.P.: Hemicellulose extraction of mixed southern hardwood with water at 150 ??C: Effect of time. Ind. Eng. Chem. Res. 47, 7031-7037 (2008). doi:10.1021/ie8007105

17. Cullis, I.F., Saddler, J.N., Mansfield, S.D.: Effect of Initial Moisture Content and Chip Size on the Bioconversion Efficiency of Softwood Lignocellulosics. Biotechnol. Bioeng. 85, 413-421 (2004). doi:10.1002/bit.10905

18. Demartini, J.D., Foston, M., Meng, X., Jung, S., Kumar, R., Ragauskas, A.J., Wyman, C.E.: How chip size impacts steam pretreatment effectiveness for biological conversion of poplar 
wood into fermentable sugars. Biotechnol. Biofuels. 8, 1-16 (2015). doi:10.1186/s13068015-0373-1

19. Monavari, S., Galbe, M., Zacchi, G.: Impact of impregnation time and chip size on sugar yield in pretreatment of softwood for ethanol production. Bioresour. Technol. 100, 63126316 (2009). doi:10.1016/j.biortech.2009.06.097

20. Agreste Lorraine: La récolte de bois récoltés en Lorraine en 2014. (2015)

21. Institut Technologique FCBA (Forêt Cellulose Bois-construction Ameublement): Mémento FCBA. (2016)

22. Kirikyali, N., Connerton, I.F.: Xylan degrading enzymes from fungal sources. J. Proteomics Enzymol. 4, 1-11 (2015). doi:10.4172/2470-1289.1000118

23. Venkateswar Rao, L., Goli, J.K., Gentela, J., Koti, S.: Bioconversion of lignocellulosic biomass to xylitol: An overview, (2015)

24. Fengel, D., Wegener, G.: Wood: chemistry, ultrastructure, reactions. (1989)

25. Demirbas, A.: Biofuels from beech wood via thermochemicals conversion methods. Energy Sources, Part A Recover. Util. Environ. Eff. 32, 346-354 (2010). doi:10.1080/15567030802466201

26. Yildiz, U.C., Yildiz, S., Gezer, E.D.: Mechanical and chemical behavior of beech wood modified by heat. Wood Fiber Sci. 37, 456-461 (2005)

27. Bodirlau, R., Teaca, C. a, Spiridon, I.: Chemical modification of beech wood: Effect on thermal stability. BioResources. 3, 789-800 (2008). doi:10.15376/biores.3.3.789-800

28. Heitz, M., Capek-Ménard, E., Koeberle, P.G., Gagné, J., Chornet, E., Overend, R.P., Taylor, J.D., Yu, E.: Fractionation of Populus tremuloides at the pilot plant scale: Optimization of steam pretreatment conditions using the STAKE II technology. Bioresour. Technol. 35, 2332 (1991). doi:10.1016/0960-8524(91)90078-X

29. Schultz, T.P., Biermann, C.J., McGinnins, G.D.: Steam explosion of mixed hardwoods chips as a biomass pretreatment. Ind. Eng. Prod. Res. Dev. 22, 344-348 (1983)

30. Schultz, T.P., Curry Templeton, M., Biermann, C.J., McGinnis, G.D.: Steam Explosion of Mixed Hardwood Chips, Rice Hulls, Corn Stalks, and Sugar Cane Bagasse. J. Agric. Food Chem. 32, 1166-1172 (1984). doi:10.1021/jf00125a058

31. Nabarlazt, D., Farriol, X., Montane, D.: Kinetic Modeling of the Autohydrolysis of Lignocellulosic Biomass for the Production of Hemicellulose-Derived Oligosaccharide . Ind. Eng. Chem. Res. 43, 4124-4131 (2004). doi:10.1021/ie034238i 
32. Stoffel, R.B., Neves, P.V., Felissia, F.E., Ramos, L.P., Gassa, L.M., Area, M.C.: Hemicellulose extraction from slash pine sawdust by steam explosion with sulfuric acid. Biomass and Bioenergy. 107, 93-101 (2017). doi:10.1016/j.biombioe.2017.09.019

33. Lam, P.S., Lam, P.Y., Sokhansanj, S., Lim, C.J., Bi, X.T., Stephen, J.D., Pribowo, A., Mabee, W.E.: Steam explosion of oil palm residues for the production of durable pellets. Appl. Energy. 141, 160-166 (2015). doi:10.1016/j.apenergy.2014.12.029

34. Cantarella, M., Cantarella, L., Alberto Gallifuoco, A.S., Alfani, F.: Effect of Inhibitors Released during Steam-Explosion Treatment of Poplar Wood on Subsequent Enzymatic Hydrolysis and SSF. Biotechnol. Prog. 20, 200-206 (2004). doi:10.1021/bp0257978 


\begin{tabular}{|c|c|c|c|c|}
\hline $\mathrm{t}_{\mathrm{s}}(\mathrm{min})$ & 150 & 170 & 190 & 210 \\
\hline 2.5 & 1.87 & 2.46 & 3.05 & 3.64 \\
\hline 5 & 2.17 & 2.76 & 3.35 & 3.94 \\
\hline 10 & 2.47 & 3.06 & 3.65 & 4.24 \\
\hline 15 & 2.65 & 3.24 & 3.83 & 4.41 \\
\hline
\end{tabular}

Table 1 Severity factor $\left(R_{0}\right)$ values Software used: Microsoft Word 


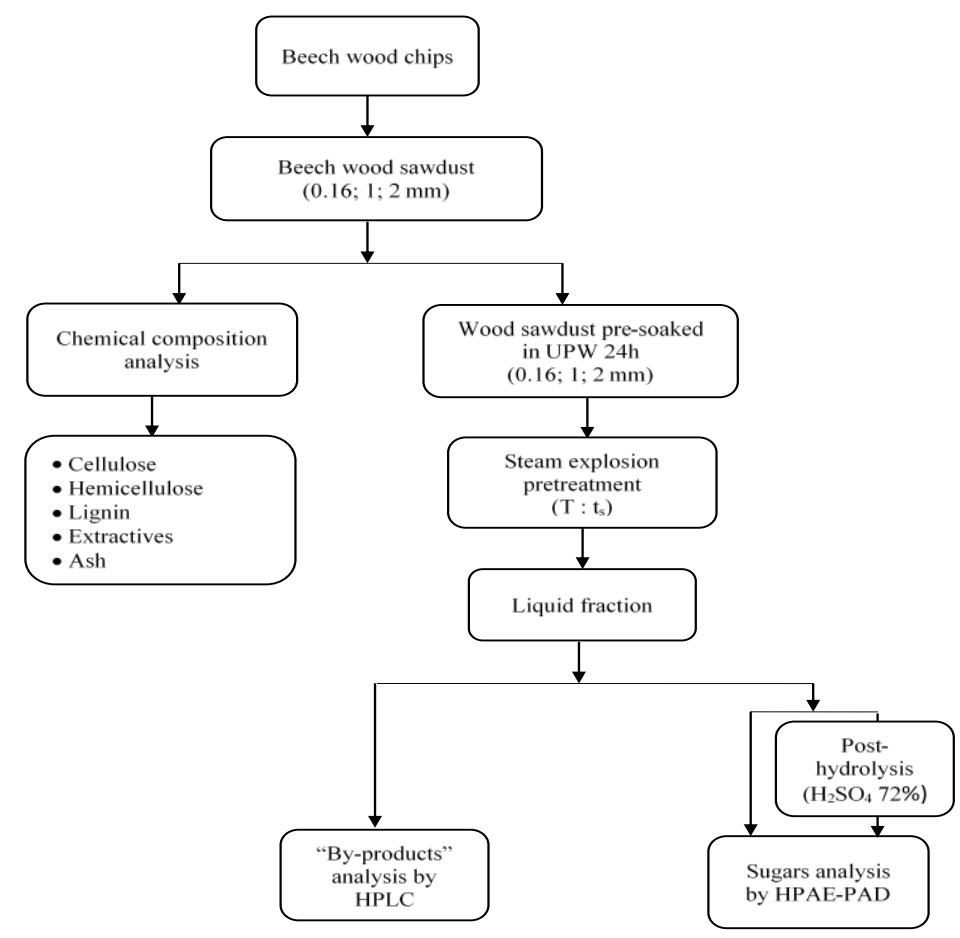

Figure 1 Flowchart of beech sawdust pretreatment.

Software used: Microsoft Word 


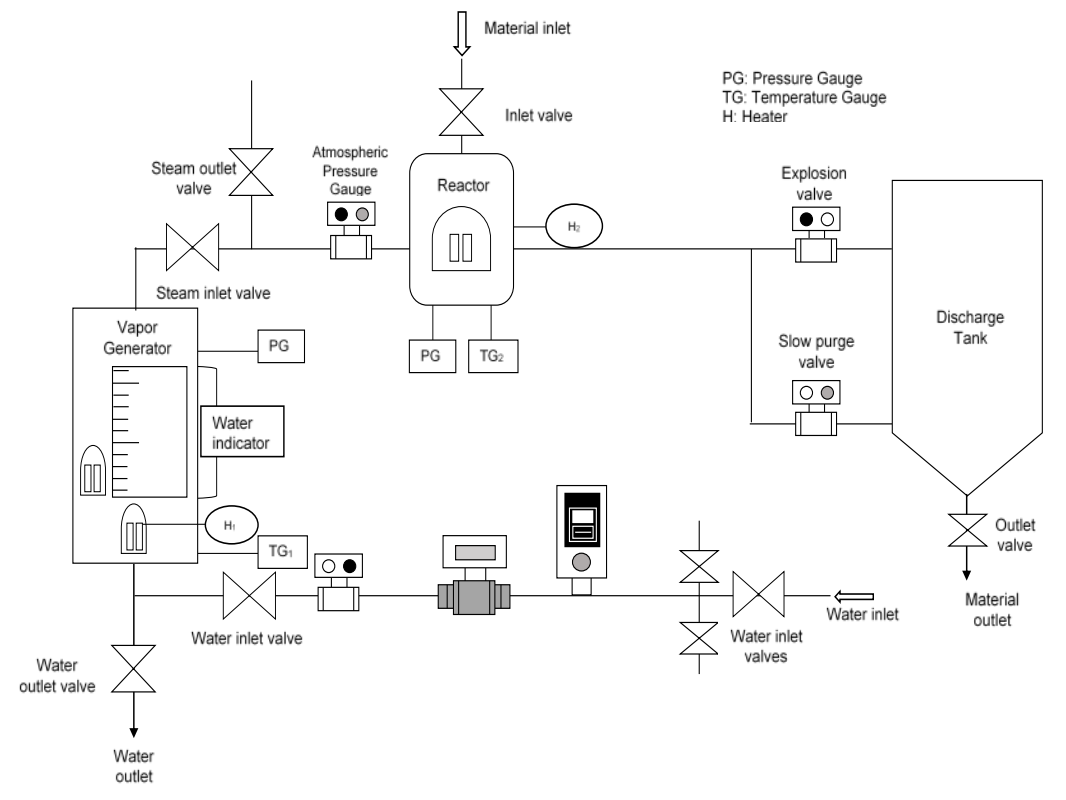

Figure 2 The schematic of steam-explosion pretreatment system. Software used: Microsoft Word 


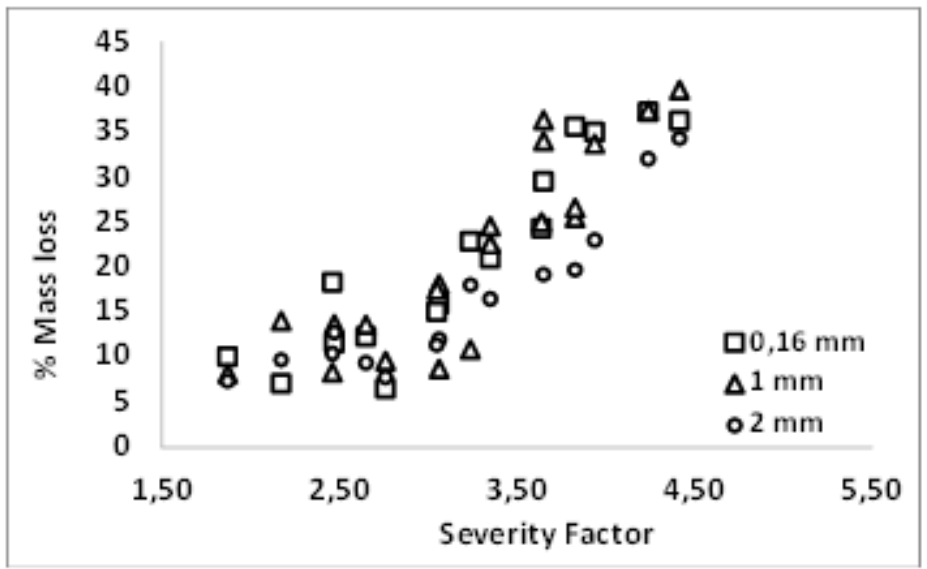

Figure 3 Mass loss vs $\mathrm{R}_{0}$.

Software used: Microsoft Excel

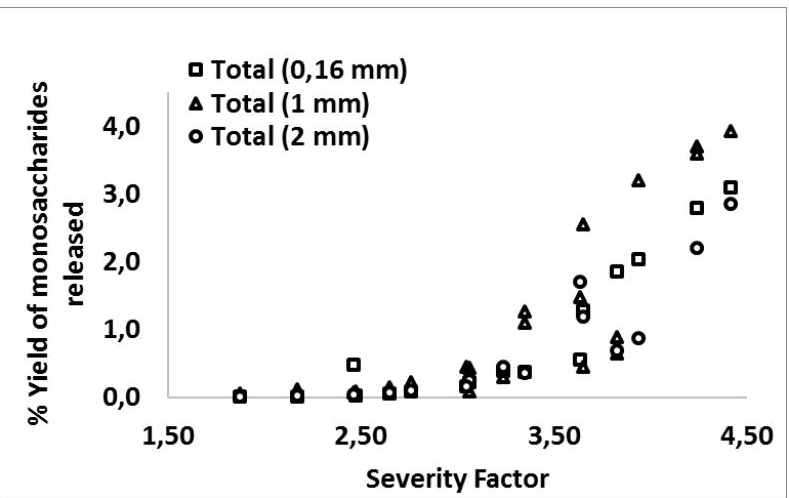


B.

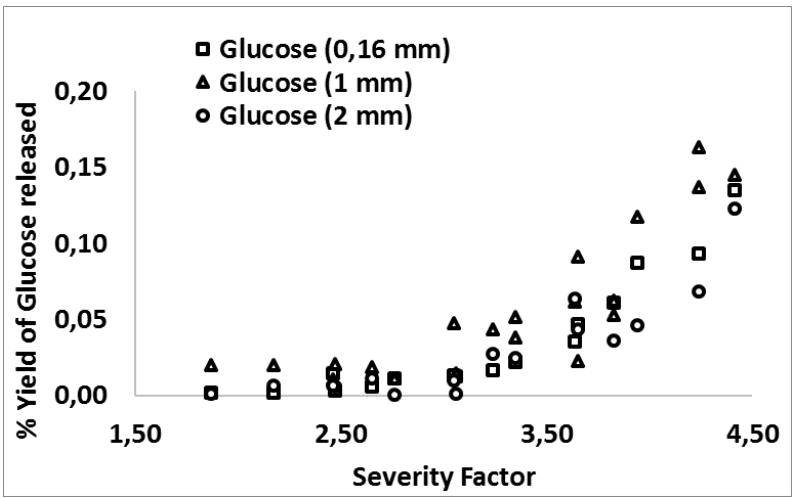

C.

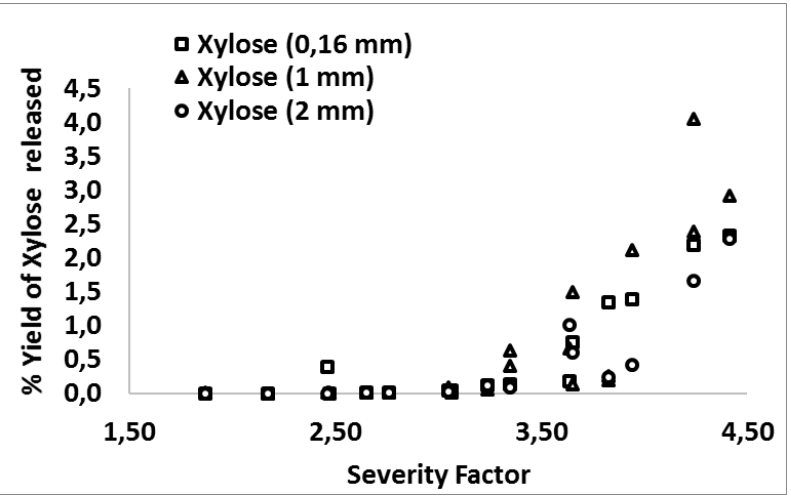

Figure 4 Yield of monosaccharides released in the liquid phase vs $R_{0}$. A) the total monosaccharides yields; B) the monomeric glucose; C) the monomeric xylose.

Software used: Microsoft Excel 
A.

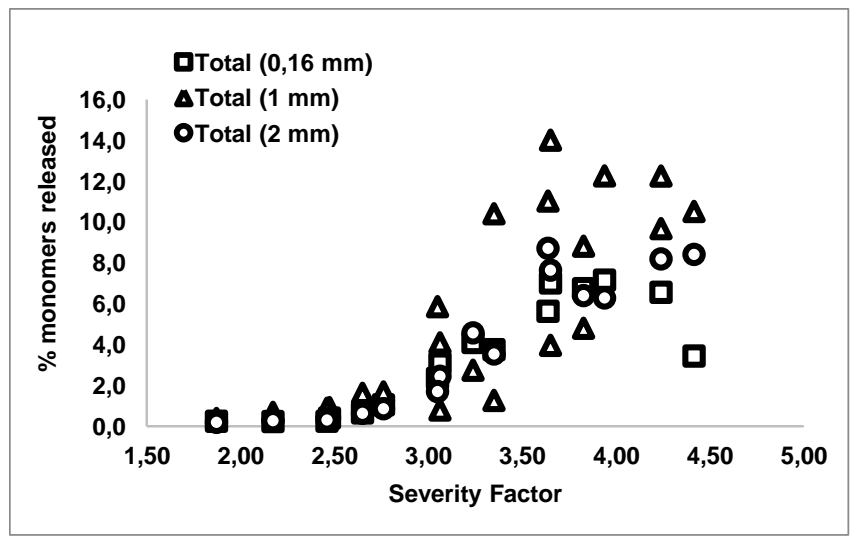

B.

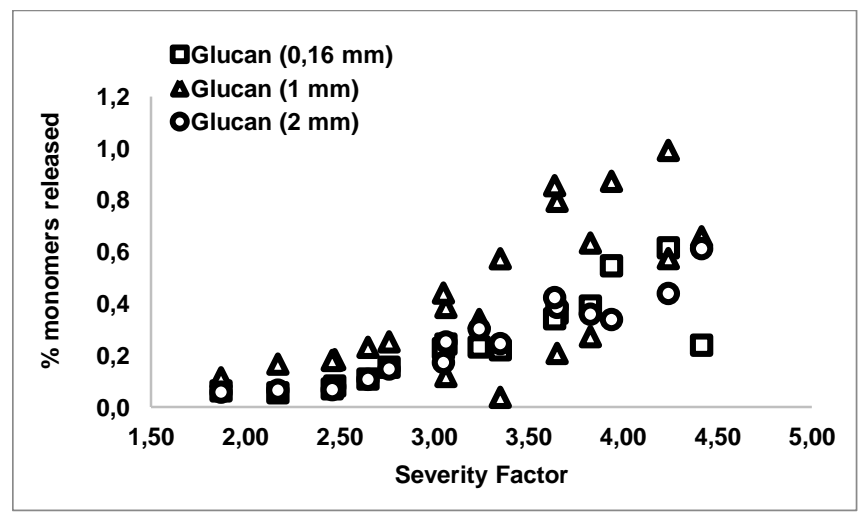

C.

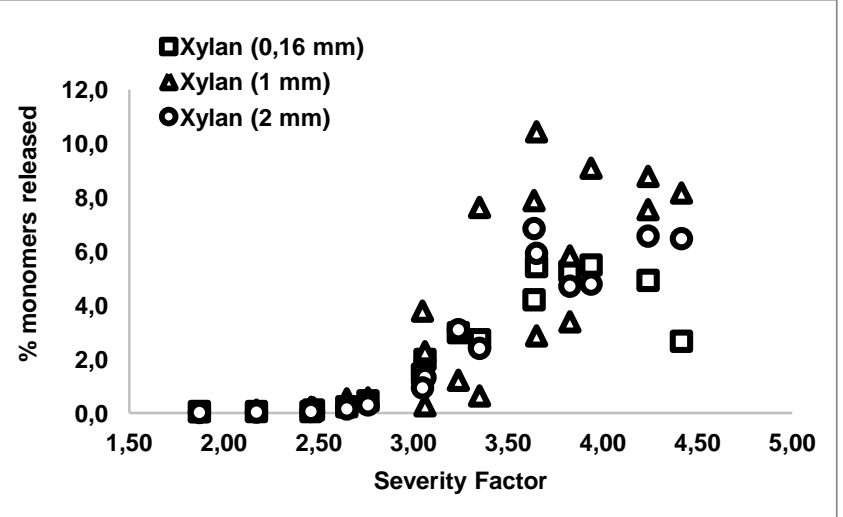

Figure 5 Yield of oligosaccharides released in the liquid phase vs $\mathrm{R}_{0}$. A) the oligomeric total sugars; B) the oligomeric glucans; C) the oligomeric xylans.

Software used: Microsoft Excel 
A.

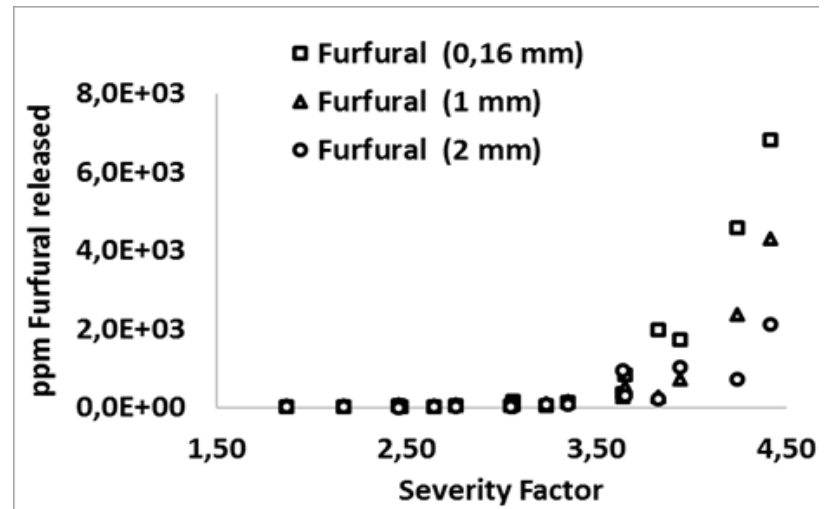

B.

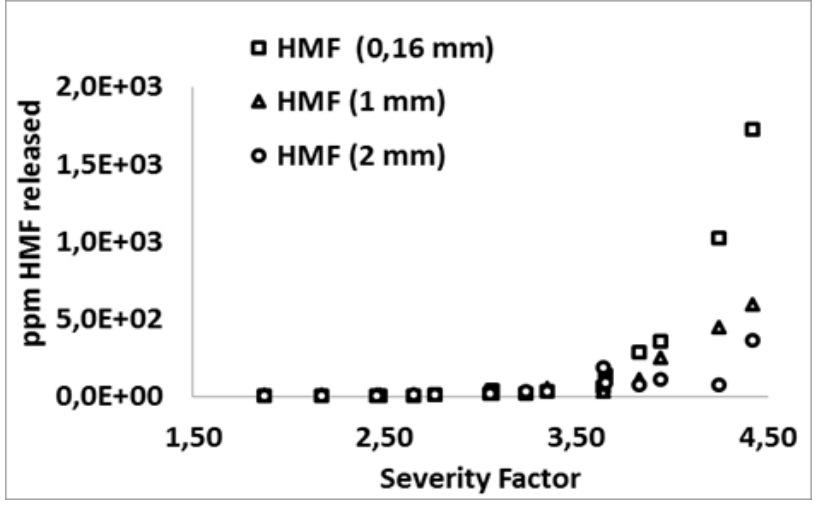

Figure 6 Yield of A) furfural and B) HMF released in the liquid phase vs $R_{0}$. Software used: Microsoft Excel 
